\title{
ПРАВОВОЕ РЕГУЛИРОВАНИЕ ПРОТИВОДЕЙСТВИЯ РЕЙДЕРСТВУ
}

Аннотация: Предметом исследования являются правовые и организационные проблемы противодействия рейдерству. Отмечается, что данная проблема подрывает основы экономической безопасности Российской Федерации, создает ряд проблем в деле развития российского предпринимательства и промышленности. Объектом исследования является круг общественных отношений, которые складываются в связи с противодействием рейдерству. В настоящей статье рассматриваются уголовно-правовые и административно-правовые средства противодействия рейдерству, при этом особое внимание уделяются совершенствованию деятельности правоохранительных органов в рассматриваемой сфере. Методологическую основу статьи составили современные достижения теории познания. В процессе исследования применялись теоретический, общефилософские методы, а также методы, используемые в конкретно-сочиологических исследованиях. Обозначенная проблема в должном порядке не решается ни в теории, ни на практике. Отмечается, что распространившаяся в России практика рейдерских захватов с противоправным использованием инструмента уголовного и административного принуждения является серьезной государственной проблемой и требует принятия срочных мер правового и организационного характера. Новизна исследования состоит в том, что в нем срормулированы конкретные предложения по совершенствованию законодательства направленного на противодействия рейдерству.

Ключевые слова: рейдер, рейдерство, собственность, захват, ответственность, принуждение, полиция, криминал, развитие, КоАП.

$\mathrm{P}$ аспространившаяся в России практика рейдерских захватов коммерческой собственности с противоправным использованием инструмента уголовного преследования является серьезной государственной проблемой и требует принятия срочных мер уголовно-правового характера.

Такое перераспределение собственности, основанное на уголовно-правовых нормах, противоречащих общеправовым и общепризнанным принципам международного права, а также на толковании, искажающем правовую норму, является, по существу, антиконституционным, не позволяет создать современную рыночную экономику, наносит ущерб самой идеи правового государства.

Очевидная неэффективность современного уголовного законодательства в сфере экономики нуждается в комплексной модернизации - пересмотре ряда положений УК РФ и УПК РФ.

Сегодня для рейдерства характерна тенденция, при которой имущество (активы) хозяйствующих субъектов незаконным путем, вопреки воле их учредителей (участников) или органов управления, посредством инициирования корпоративных конфликтов переходит в собственность других лиц, т.е. фактически захватывается.

В числе основных факторов распространения сравнительно нового криминального явления незаконного присвоения прав на владение и управ- ление хозяйствующими субъектами и их активами (рейдерства) - следует назвать существенные упущения на первоначальном этапе проведения реформ в социально-экономической, политической, правоохранительной и иных сферах государственной деятельности, значительное ослабление системы государственного регулирования и контроля, несовершенство правовой базы, отсутствие эффективной политики государственного управления в Российской Федерации. В настоящее время рейдерство как вид преступной деятельности носит организованный характер, совершается с использованием пробелов в законодательстве, с коррупционным привлечением государственных, административных и силовых ресурсов и в целом представляет реальную угрозу экономической безопасности Российской Федерации.

Фактически рейдерство стало одним из видов высокодоходного криминального бизнеса, основной формой незаконного перераспределения. перераспределения собственности после периода ее насильственного передела преступными сообществами в 1990-х гг. Беспрецедентный передел собственности направлен на захват как отдельных предприятий, так и крупных холдингов, контролирующих целые отрасли народного хозяйства. Можно говорить о второй, «теневой» приватизации, которая осуществляется не государством, а 
олигархическими группами путем изъятия у законных собственников акций и других активов приватизированных компаний и, где это возможно, государственных стратегических предприятий, включая реструктурируемые отрасли.

Характерным признаком корпоративных отношений в современной российской экономике является наличие компаний, специализирующихся в области рейдерских захватов («рейдеров»), так как полулегальные схемы захвата предприятий и вывода активов зачастую более доступны и требуют меньших затрат, чем законные способы ведения бизнеса [1].

По оценкам экспертов, криминальная деятельность преступных групп по поглощению хозяйствующих субъектов и их активов (рейдерства) приносит им доходы, сопоставимые с бюджетом некоторых субъектов РФ. Тем самым наносится огромный ущерб промышленным предприятиям, учреждениям, частным организациям и в итоге экономическому прогрессу России в целом.

В корпоративных конфликтах стали применяться такие средства, как злоупотребление правом, использование отдельными акционерами юридического лица известной неопределенности и противоречий в законодательстве в корыстных целях, так называемый корпоративный шантаж, имеющий существенные негативные последствия и направленный на создание препятствий в осуществлении акционерным обществом нормальной хозяйственной деятельности, в целях понуждения последнего к выкупу акций, принадлежащих акционеру, по цене, в значительной мере превышающей рыночную.

Рейдерские захваты и корпоративный шантаж в России связаны с такими угрозами экономической безопасности, как увеличение коррумпированности государственных служащих и представителей судейского корпуса; повышение уровня безработицы; уклонение от уплаты налогов; монополизация ряда сегментов рынка; утрата конкурентоспособности; разрушение и спад производства; дискредитация представителей федеральной и региональной власти, правоохранительных органов и судов; ухудшение инвестиционного климата; деформация правовой идеологии и распространение правового нигилизма; активизация процессов отмывания денег, полученных преступным путем. Рейдерство наносит вред государственным интересам, охраняемым законом правам отдельных юридических лиц и граждан, подрывает основы частной собственности и предпринимательства, что свидетельствует о возникновении и развитии новых форм организованной экономической преступности, ее глубоком проникновении в систему экономических отношений.

В 2008-2010 гг. вопросы противодействия рейдерству были объектом внимания высших органов власти. Одним из приоритетных направлений деятельности Правительства РФ в сфере обеспечения национальной безопасности на период до 2012 г. являлось осуществление комплекса мероприятий по противодействию криминальным захватам имущественных комплексов (рейдерству), причиняющим значительный ущерб экономике и имеющим большой общественный резонанс.

Неэффективность таких мер очевидна и подтверждается статистикой. Так, ежегодно в России лишь по 10-15\% фактов рейдерских захватов возбуждаются уголовные дела. Вследствие этого большое число лиц, совершающих их, остаются безнаказанными. Между тем, по официальным данным Национального антикоррупционного комитета России, ежегодно происходит до 730 тыс. таких захватов. Кроме того, лишь по 10-16\% возбужденных уголовных дел рассматриваемой категории выносится судебное решение. Это обусловлено в большей мере низкой эффективностью деятельности правоохранительных органов, а также несовершенством норм уголовного закона, применяемых в отношении «рейдеров».

В этих условиях стратегической государственной задачей на обозримую перспективу становится эффективное противодействие криминальному присвоению прав на владение и управление хозяйствующими субъектами и их активами.

Правоприменительная практика свидетельствует о необходимости осуществления ряда политических, организационных, социальноэкономических, законодательных и иных мер, направленных на противодействие рейдерству, снижению числа корпоративных конфликтов, защиту прав и законных интересов инвесторов. Такие меры должны носить комплексный, межотраслевой характер и учитывать охранительные и регулятивные возможности не только цивилистических отраслей права, но и права отраслей криминального цикла, в том числе уголовного права.

К сожалению, наименее соответствующим современному уровню развития экономических отношений остается уголовное законодательство. Действующий уголовный закон далеко не в полной мере выполняет свою охранительную и, как мы полагаем, регулятивную функцию в таком наиболее 
значимом сегменте экономики, как сфера корпоративных отношений. УК РФ был принят в 1996 г. в условиях иной экономической политики. В то время корпоративные отношения только зарождались, и посягающие на них преступления в нем предусмотрены не были. УПК РФ также не лишен недостатков в аспекте заявленной темы исследования.

В этой связи особое значение приобретает реформирование права отраслей криминального цикла в целях обеспечения надежной защиты прав и законных интересов хозяйствующих субъектов и иных участников корпоративных отношений от рейдерства и корпоративного шантажа с учетом положительного опыта англосаксонской и континентальной моделей права.

Особенность экономической ситуации в России в настоящее время такова, что значительная часть гражданско-правовых институтов не может нормально функционировать без административно-правового, уголовно-правового, уголовно-процессуального, криминалистического и криминологического обеспечения, которое необходимо для становления цивилизованных рыночных отношений. Вместе с тем совершенствование норм об уголовной или административной ответственности лиц, совершающих противоправные деяния в сфере корпоративных отношений, невозможно без одновременного внесения изменений и дополнений в корпоративное законодательство.

Традиционный, «классический» подход к предупреждению преступлений, основанный на социальной профилактике, является оптимальным в условиях стабильного государства, последовательно осуществляющего социальную политику. В современной России, где процессы криминализации экономики имеют тенденцию к расширению, на первый план выходит декриминализация экономических отношений. В этом отношении целесообразным представляется проведение оперативно-профилактических операций.

Идеология стратегии противодействия рейдерству должна включать: а) оптимизацию роли государства в регулировании экономических процессов; б) ориентацию прежде всего на достижение национальных (а не частных и корпоративных) интересов.

Необходима разработка взвешенной и ресурсно-обеспеченной целевой программы по противодействию преступности в сфере корпоративных отношений в целом и преступлениям, связанным с криминальным присвоением прав на владение и управление хозяйствующими субъектами и их ак- тивами (рейдер-ством), которая должна быть сориентирована на устранение всего комплекса факторов, приводящих к разрастанию, укреплению и появлению новых, изощренных видов организованной экономической преступности. К разработке такой программы следует привлечь квалифицированные научные коллективы страны, опытных специалистов-практиков, представляющих различные отрасли знаний: экономику, право, управление, социологию, политологию и др.

Требуется внесение ряда изменений в законодательство. Причем противодействие рейдерству будет эффективным лишь при одновременном совершенствовании уголовного, уголовно-процессуального, гражданского, административно-правового и другого законодательства.

Определенные шаги по пути совершенствования уголовно-правового механизма противодействия рейдерству были предприняты в 2009-2010 г. Однако этого оказалось недостаточно для того, чтобы нейтрализовать негативную тенденцию ежегодного увеличения числа рейдерских захватов.

Данные официальной статистики не соответствуют действительному положению дел с преступлениями на рынке ценных бумаг, являющимися высоколатентными в силу разных причин, в том числе из-за несовершенства уголовного закона. Требуется внесение изменений в ст. 185 УК РФ, предусматривающую ответственность за злоупотребления при эмиссии ценных бумаг. Сроки наказания за совершение этих деяний не соответствуют общественной опасности содеянного, и категорийность деяния определена неправильно, что не способствует построению эффективной уголовной политики ротиводействия экономической преступности в целом и рейдерству в частности.

Завышен и размер крупного ущерба. Это позволяет виновным в злоупотреблениях при эмиссии ценных бумаг избегать ответственности. Ущерб должен быть аналогичным тому, который был ранее определен в отношении большинства преступлений в сфере экономической деятельности (т.е. превышающим 250 тыс. руб. прим. к ст. 169 УК РФ в ранее действовавшей ред.).

Аналогичные замечания (в части необоснованного завышения законодателем размера крупного ущерба и несоответствия максимальных сроков наказания общественной опасности содеянного) следует высказать и в отношении ст. $185^{1}$, $185^{2}, 185^{3}$ и $185^{4}$ УК РФ.

Кроме того, конструкция ст. $185^{2}, 185^{3}$ и $185^{4}$ УК РФ является, на наш взгляд, ошибочной и долж- 
на быть изменена с учетом следующих правил: основной состав - формальный, квалифицированный состав - материальный. В этих целях необходимо исключить из первых частей соответствующих статей указание на причинение крупного ущерба или извлечение дохода в крупном размере.

Формулирование обозначенных составов преступлений как формальных позволит осуществлять уголовное преследование злоумышленников уже на этапе фальсификации соответствующих решений.

Требуется также криминализировать деяния, предусмотренные ст. 170 , 185², 1854, 185 УК РФ, совершенные в составе группы лиц по предварительному сговору, организованной группы или преступного сообщества. Это обусловлено тем, что рейдерские захваты и другие корпоративные преступления совершаются не единолично, порой численность организованных групп составляет несколько десятков человек.

Предлагается также дополнить ч. 1 ст. $185^{5}$ УК РФ после слов «или об избрании управляющей организации либо управляющего» словами «или об утверждении реестродержателя ценных бумаг общества и условий договора с ним, а также о расторжении договора с ним», а также после слов «путем размещения дополнительных акций» словами «или об определении цены имущества, цены размещения и выкупа эмиссионных ценных бумаг».

В целях криминализации деяний, направленных на инициирование и использование заведомо неправосудных решений суда по гражданскому делу,

целесообразно дополнить УК РФ ст. 301 «Фальсификация доказательств по гражданскому делу», а также внести изменения в ст. 303 УК РФ.

Использование неправосудного решения в целях рейдерского захвата также должно быть криминализировано. В связи с этим необходимо дополнить УК РФ ст. $187^{1}$ «Использование заведомо подложного или неправосудного судебного решения».

Актуальным представляется внесение в УК РФ нормы, криминализирующей корпоративный шантаж, - ст. 201' «Злоупотребление правами участника (акционера) юридического лица».

В целях единообразного понимания содержания понятия «ущерб» в правоприменительной практике по отношению к преступлениям в сфере корпоративных отношений необходимо дополнить примечание к ст. 169 УК РФ абзацем следующего содержания:

«Под ущербом в статьях главы 22 и 23 настоящего Кодекса понимаются материальный и другие виды имущественного вреда (убытков). В содержа- ние ущерба (убытков) включается как реальный ущерб, так и упущенная выгода. Не включаются в ущерб нематериальные виды вреда, в том числе моральный вред».

В целях повышения уровня защищенности прав и законных интересов инвесторов необходимо дополнить УК РФ следующими

статьями:

ст. $201^{2}$, предусматривающей ответственность за умышленное нарушение членами органов управления хозяйственного общества правил одобрения крупной сделки или сделки, в совершении которой имеется заинтересованность;

ст. $201^{3}$, предусматривающей ответственность за искажение данных финансовой или иной отчетности хозяйственного общества, ценные бумаги которого обращаются на торгах организаторов торговли на рынке ценных бумаг;

ст. $201^{4}$, устанавливающей ответственность за злоупотребление полномочиями оценщика, за заведомо недостоверную оценку имущества лицом, уполномоченным в соответствии с законодательством РФ осуществлять оценочную деятельность.

Необходимо также дополнить УК РФ уголовно-правовыми мерами, влекущими неблагоприятные правовые последствия для юридических лиц, отнеся такие последствия не к уголовному наказанию, а иным мерам уголовной ответственности, предусмотренным в разд. VI УК РФ. Например, посредством дополнения данного раздела гл.15 «Меры уголовно-правового характера, применяемые к юридическим лицам».

Требуется закрепить право прокурора обращаться в кассационную или надзорную инстанцию арбитражного суда или суда общей юрисдикции с представлением об отмене неправосудного решения по гражданскому делу, препятствующего предъявлению обвинения, вынесению обвинительного приговора или иному решению уголовного дела по существу. Неправосудные решения судов по гражданским делам затрагивают не только частные, но и публичные интересы, и именно прокурор как должностное лицо, осуществляюеее от имени государства надзор за законностью, должен быть наделен данным правом.

Кроме того, представляется необходимым внести изменения в ст. 115 УПК РФ, закрепив право наложения ареста на имущество при отсутствии подозреваемых и обвиняемых в случае установления, что такое имущество получено преступным путем. Данная мера будет реализовываться на стадии следствия с тем, чтобы лишить злоумышлен- 
ников возможности распорядиться похищенным имуществом (продать его добросовестному приобретателю и т.п.).

По нашему мнению, несовершенным является порядок возбуждения уголовных дел по признакам составов преступлений, предусмотренных гл.23 УК РФ: уголовное дело может возбуждаться только по заявлению организации, интересам которой причинен вред, или с ее согласия. Наиболее существенный недостаток уголовного закона заключается в неверном указании на субъект согласования решения о возбуждении уголовного дела. Руководителям коммерческих и иных организаций вменено в обязанность давать согласие на возбуждение уголовного дела в случае совершения указанных преступлений. Между тем, как свидетельствуют данные, полученные в ходе изучения и обобщения следственной и судебной практики, более 70\% злоупотреблений своими полномочиями совершают эти лица. Получается, что они должны давать согласие на возбуждение уголовного дела против самих себя.

Учитывая сказанное, необходимо по аналогии с гражданским законодательством закрепить правомочие подавать заявление о возбуждении уголовного дела в отношении виновных указанных субъектов члену (членам) коллегиального исполнительного органа (совета директоров, наблюдательного совета) общества; акционеру (акционерам), владеющему в совокупности не менее чем $1 \%$ размещенных обыкновенных акций общества; участнику общества с ограниченной (дополнительной) ответственностью.
Кроме того, использование в ст. 23 УПК РФ термина «руководитель организации» не согласуется с гражданским законодательством и соответствующими законами о хозяйственных обществах, где такое лицо именуется «лицом, осуществляющим функции единоличного исполнительного органа общества». Поэтому УПК РФ должен быть приведен в соответствие с нормами гражданского законодательства.

Для реализации обозначенных предложений необходимо внесение изменений в ст. 23 УПК РФ «Привлечение к уголовному преследованию по заявлению коммерческой или иной организации» и в примечание 2 к ст. 201 УК РФ «Злоупотребление полномочиями».

Целесообразно также обеспечить единообразие терминологии гражданского и уголовного законодательства. Экономические преступления по своей природе находятся на «стыке» отраслей права, поэтому необходимо минимизировать ситуации, когда гражданское законодательство препятствует реализации уголовно-правовых норм.

Высказанные нормотворческие предложения, безусловно, требуют оценки ученых и иных специалистов. Необходимо также учитывать, что частые изменения законодательства не способствуют его стабильности и негативно влияют на правоприменительную практику. В связи с этим предложения, высказанные в данной статье, должны, по нашему мнению, реализовываться в рамках единой государственной программы противодействия преступности в сфере корпоративных отношений.

\section{Библиография:}

1. Максимов С.В. Госрейдерство как средство нелегального перераспределения собственности // Криминологический журнал. - 2008. - № 2.

2. Костенников М.В., Куракин А.В., Кошелев И.Н. Административно-правовое регулирование обеспечения собственной безопасности и противодействия коррупции в органах внутренних дел (ч. 3 окончание начало в № 1 , 2 - 2011 г.) // Административное и муниципальное право.-2011.-4.-С. 52-61.

3. М.В. Костенников, А.В. Куракин, И.Н. Кошелев Административно-правовое регулирование обеспечения собственной безопасности и противодействия коррупции в органах внутренних дел (ч. 2). // Административное и муниципальное право.-2011.-2.-С. 38-45.

4. Костенников М.В., Куракин А.В. Административно-правовое противодействие коррупции в системе государственной службы и в деятельности сотрудников полиции Российской Федерации и зарубежных государств. // Полицейская деятельность.-2011.-1.-С. 10-16.

5. Бочаров С.Н. К вопросу о взаимодействии органов внутренних дел и частных охранных организаций // Административное и муниципальное право.-2012.-12.-С. 61-63.

6. Е. А. Рыбакова Криминальный захват недвижимости // Союз криминалистов и криминологов.-2013.-2.-С. 159-162.

7. Куракин А.В. Административно-правовые аспекты юридической ответственности в механизме противодействия коррупции в системе государственной службы Российской Федерации // NB: Административное право и практика администрирования.-2013.-7.-C. 137-157. DOI: 10.7256/2306-9945.2013.7.9954. URL: http://www.enotabene.ru/al/article_9954.html

8. Куракин А.В., Костенников М.В. Административно-правовое противодействие коррупции в системе государственной службы и в деятельности сотрудников полиции Российской Федерации и зарубежных государств // 
Административное и муниципальное право 1 (85) 2015

Полицейская и следственная деятельность.-2013.-1.-C. 65-83. DOI: 10.7256/2306-4218.2013.1.735. URL: http:// www.e-notabene.ru/pm/article_735.html

9. М.В. Костенников К вопросу о противодействии коррупции в полиции // Административное и муниципальное право.-2013.-1.-С. 49-50. DOI: 10.7256/1999-2807.2013.01.9.

10. Костенников М.В., Куракин А.В., Ватель А.Ю. Антикоррупционные и этические стандарты служебного поведения государственных гражданских служащих // NB: Административное право и практика администрирования.2014.-4.-C. 15-39. DOI: 10.7256/2306-9945.2014.4.12248. URL: http://www.e-notabene.ru/al/article_12248.html

11. О. Н. Амвросова, Г. Ю. Атаян Влияние зарубежного опыта на экономическую деятельность российского государства во второй половине XVIII в. // Право и политика.-2011.-11.-С. 1931-1935.

\section{References (transliterated):}

1. Maksimov S.V. Gosreiderstvo kak sredstvo nelegal'nogo pereraspredeleniya sobstvennosti // Kriminologicheskii zhurnal. 2008. - № 2.

2. Kostennikov M.V., Kurakin A.V., Koshelev I.N. Administrativno-pravovoe regulirovanie obespecheniya sobstvennoi bezopasnosti i protivodeistviya korruptsii v organakh vnutrennikh del (ch. 3 okonchanie nachalo v № 1 , 2 - 2011 g.) // Administrativnoe i munitsipal'noe pravo.-2011.-4.-C. 52-61.

3. M.V. Kostennikov, A.V. Kurakin, I.N. Koshelev Administrativno-pravovoe regulirovanie obespecheniya sobstvennoi bezopasnosti i protivodeistviya korruptsii v organakh vnutrennikh del (ch. 2). // Administrativnoe i munitsipal'noe pravo.-2011.-2.-C. 38-45.

4. Kostennikov M.V., Kurakin A.V. Administrativno-pravovoe protivodeistvie korruptsii v sisteme gosudarstvennoi sluzhby i v deyatel'nosti sotrudnikov politsii Rossiiskoi Federatsii i zarubezhnykh gosudarstv. // Politseiskaya deyatel'nost'.-2011.1.-C. 10-16.

5. Bocharov S.N. K voprosu o vzaimodeistvii organov vnutrennikh del i chastnykh okhrannykh organizatsii // Administrativnoe i munitsipal'noe pravo.-2012.-12.-C. 61-63.

6. E. A. Rybakova Kriminal'nyi zakhvat nedvizhimosti // Soyuz kriminalistov i kriminologov.-2013.-2.-C. 159-162.

7. Kurakin A.V. Administrativno-pravovye aspekty yuridicheskoi otvetstvennosti v mekhanizme protivodeistviya korruptsii v sisteme gosudarstvennoi sluzhby Rossiiskoi Federatsii // NB: Administrativnoe pravo i praktika administrirovaniya.2013.-7.-C. 137-157. DOI: 10.7256/2306-9945.2013.7.9954. URL: http://www.e-notabene.ru/al/article_9954.html

8. Kurakin A.V., Kostennikov M.V. Administrativno-pravovoe protivodeistvie korruptsii v sisteme gosudarstvennoi sluzhby i v deyatel'nosti sotrudnikov politsii Rossiiskoi Federatsii i zarubezhnykh gosudarstv // Politseiskaya i sledstvennaya deyatel'nost'.-2013.-1.-C. 65-83. DOI: 10.7256/2306-4218.2013.1.735. URL: http://www.e-notabene.ru/pm/article_735.html

9. M.V. Kostennikov K voprosu o protivodeistvii korruptsii v politsii // Administrativnoe i munitsipal'noe pravo.-2013.-1.C. 49-50. DOI: 10.7256/1999-2807.2013.01.9.

10. Kostennikov M.V., Kurakin A.V., Vatel' A.Yu. Antikorruptsionnye i eticheskie standarty sluzhebnogo povedeniya gosudarstvennykh grazhdanskikh sluzhashchikh // NB: Administrativnoe pravo i praktika administrirovaniya.-2014.4.-C. 15-39. DOI: 10.7256/2306-9945.2014.4.12248. URL: http://www.e-notabene.ru/al/article_12248.html

11. O. N. Amvrosova, G. Yu. Atayan Vliyanie zarubezhnogo opyta na ekonomicheskuyu deyatel'nost' rossiiskogo gosudarstva vo vtoroi polovine XVIII v. // Pravo i politika.-2011.-11.-C. 1931-1935. 